\title{
PENDAMPINGAN MASYARAKAT DALAM MEMAHAMI AGAMA ISLAM MELALUI STRATEGI DAKWAH PERSUASIF DI DESA KAYUKEBEK
}

\author{
Hufron 1) Ahmad Muthohar 2) Khoirul Anwar ${ }^{3)}$ Endang Tyasmaning ${ }^{4)}$ \\ 1) Institut Agama Islam Sunan Kalijogo Malang, 2) Universitas Negeri Malang Malang, 3) \\ Institut Agama Islam Sunan Kalijogo Malang \\ 1).hufron.iaiskj@gmail.com, 2) muthohar.ahmad@gmail.com, 3) \\ khoirulanwar@iaiskjmalang.ac.id, endang@gmail.com ${ }^{4)}$
}

\begin{abstract}
Abstrak: Lingkungan dan suasana pedesaan yang tentram tentunya juga memengaruhi perilaku dan sifat masyarakat. Kerukunan dan toleransi antar ummat beragama sangat terjaga dengan baik. Hampir tidak pernah ada gesekan yang terjadi antara umat Islam dan Hindu selama ini. Hal itu juga merupakan salah satu faktor yang membuat dakwah islam bisa dengan tenang disebarkan dan diterima oleh banyak orang.

Para Dai di Desa Kayukebek menggunakan cara-cara yang persuasif untuk menyebarkan dakwah islam, sehingga masyarakat awam dapat dengan nyaman memperoleh ilmu. Strategi dakwah di desa Kayukebek tidak pernah menggunakan cara-cara yang 'kasar' dan kaku untuk berdakwah. Yang mana jika hal itu dilakukan, masyarakat awam akan menghindar dan pada akhirnya akan semakin sulit untuk dirangkul hal tersebut termasuk dari salah satu cara dakwah persuasif.

Dakwah persuasif perlu diperhatikan prinsip-prinsip dakwah persuasif yaitu qaulan layyinan, qaulan sadidan, qaulan maysuran, qaulan baligha, qulan ma'rufa, qaulan karima dan tahapan perubahan $\operatorname{mad}^{\prime} u$ yaitu pengetahuan, sikap, dan perilaku mereka.
\end{abstract}

\section{Kata Kunci: Strategi Dakwah, dakwah persuasif}

\begin{abstract}
The peaceful rural environment and atmosphere also affects the behavior and nature of the community. Harmony and tolerance between religious communities is very well maintained. There has hardly been any friction between Muslims and Hindus during this time. It is also one of the factors that allows the propagation of Islam to be calmly spread and accepted by many people.

The Dais in Kayukebek Village use persuasive methods to spread Islamic da'wah, so that the common people can comfortably gain knowledge. The da'wah strategy in Kayukebek village never uses "rough" and rigid methods for preaching. Which if this is done, the general public will avoid it and in the end it will be increasingly difficult to embrace this, including one of the persuasive ways of preaching.

Persuasive da'wah needs to pay attention to the principles of persuasive da'wah, namely qaulan layyinan, qaulan sadidan, qaulan maysuran, qaulan baligha, qulan ma'rufa, qaulan karima and the stages of change in mad'u, namely their knowledge, attitudes and behavior.
\end{abstract}

Keywords: Da'wah Strategy, persuasive da'wah 


\section{PENDAHULUAN}

Islam merupakan agama yang rahmatan lil alamin, agama yang memberikan rahmat bagi seluruh alam, maka sudah tentu jika turunnya agam Islam kepada Nabi Muhammad SAW adalah untuk seluruh ummat manusia tanpa terkecuali. Tanpa memandang ras, golongan, negara, usia, gender, maupun suku. Semua berhak mendapatkan bimbingan dan petunjuk agama Islam dengan sebenar-benarnya. ${ }^{1}$

Islam juga merupakan agama dakwah, artinya selalu mendorong pemeluknya untuk senantiasa akif dalam melakukan kegiatan dakwah, menyebarkan prinsip-prinsip Islam yang sesuai dengan alquran, dan hadits. Seperti halnya saat agama Islam masuk ke Indonesia. Islam masuk ke Indonesia dngan berbagai macam cara:

\section{Perdagangan}

Islam masuk di Indonesia salah satunya dengan perdagangan. Sudah tidak diragukan lagi jika jauh sebelum Islam masuk pada abad ke 7 masehi, Nusantara sudah menjadi kepulauan yang dilintasi oleh berbagai macam kapal yang membawa barang dagangan dari banyak bangsa. Para pedagang tersebut transit di Indonesia mengumpulan logistic untuk kembali melanjutkan pelayaran.

Karena para pedagang yang berasal dari berbagai daerah tersebut datang menggunakan kapal laut yang masih mengandalkan hembusan angin laut maka untuk kembali melanjutkan pelayaran tentunya mereka juga menunggu datangnya arah angina yang tepat terlebih dahulu, dan hal itu membutuhkan waktu yang tidak sebentar dan bahkan hingga berbulan-bulan.

Oleh karena harus menunggu waktu yang tepat untuk kembali melanjutkan pelayaran, para saudagar tersebut menetap di Nusantara selama waktu penantian tersebut. Dan dalam waktu singgahnya yang tidak sebentar itu, para saudagar dari berbagai bangsa tersebut secara tidak langsung membawa budaya dari bangsa mereka ke bumi nusantara. Tentu mereka juga membawa kepercayaan dan agama mereka, menyebarkan dan mengenalkan kepada masyarakat sekitar, Tak terkecuali agama Islam.

\footnotetext{
${ }^{1}$ Ilham, “Peranan Penyuluh Agama Islam Dalam Dakwah,” Jurnal Alhadharah 17, no. 33 Januari-Juni (2018): 49-80.
} 


\section{Perkawinan}

Para saudagar yang beragama islam saat singgah di Nusantara kebanyakan melakukan perkawinan karena memang waku transit yang lama. Para saudagar tersebut menikahi perempuan-perempuan nusantara. Dan sebelum menikah, perempuan-perempuan yang belum beragama islam diminta untuk masuk dalam agama islam dan mengucapkan syahadat tanpa paksaan sedikitpun sebagai pertanda jika mereka menerima islam sebagai agama mereka.

Dengan cara inilah agama islam semakin besar dengan membentuk komunitas kecil di pesisir sehingga terus terjadi perkawinan dan lambat laun menjadi sebuah kerajaan islam.

\section{Pendidikan}

Penyebaran Islam melalui pendidikan dilakukan melalui pesantrenpesantren, khususnya oleh para kyiai. Semakin terkenal kyiai yang mengajar di sebuah pesantren itu, semakin besar pula pengaruh pesantren tersebut di tengahtengah masyarakat.

Beberapa pesantren yang terkenal di Indonesia diantaranya Pesantren Ampel Denta, milik Sunan Ampel (Raden Rahmat) dan Pesantren Sunan Giri milik Sunan Giri, yang kebanyakan muridnya berasal dari Maluku. Disamping mengajar di pesantren-pesantren, para kyiai juga sering kali menjadi penasehat para raja ataupun bangsawan

\section{Tasawwuf}

Penyebaran Islam yang tidak kalah pentingnya ialah melalui tasawuf. Tasawuf ialah ajaran atau cara untuk mendekatkan diri kepada Allah. Tasawuf lebih memudahkan orang yang telah mempunyai dasar ketuhanan lain untuk mengerti dan menerima ajaran agama Islam.

Disamping itu, ajaran tasawuf ini memelihara unsur-unsur budaya sebelum Islam diteruskan dalam kehidupan Islam, sehingga Islam mudah diterima oleh masyarakat. Ajaran tasawuf ini banyak di jumpai dalam cerita-cerita babad dan hikayat masyarakat setempat. Beberapa tokoh penyebar tasawuf 
diantaranya: Hamzah Fansuri, Syamsuddin, Syekh Abdul Shamad, dan Nurdin alRaniri.

\section{Kesenian}

Penyebaran agama Islam di Indonesia terlihat juga dalam kesenian Islam, seperti peninggalan seni bangunan, seni musik, seni pahat, dan seni sastra. Hasilhasil karya seni ini dapat dilihat pada bangunan masjid-masjid kuno di Demak, Banten, Cirebon dan Aceh.

\section{Politik}

Seorang raja mempunyai kekuasaan dan pengaruh yang besar dan memegang peranan penting dalam proses penyebaran agama Islam tersebut. Jika raja sebuah kerajaan memeluk agama Islam, maka rakyatnya akan memeluk agama Islam juga.

Alasannya karena masyarakat Indonesia memiliki kepatuhan yang tinggi terhadap rajanya. Demi kepentingan politik maka Raja akan mengadakan perluasan wilayah kerajaan, yang diikuti dengan penyebaran agama Islam.

\section{Dakwah}

Pendatang Muslim yang singgah di Indonesia baik yang menetap maupun yang tidak menetap, sebagian dari mereka memang benar-benar sengaja dan berniat untuk berdakwah. Penyebaran Islam melalui berdakwah, bukan hanya dilakukan oleh pendatang dari luar Indonesia.

Melainkan, Santri yang mengenyam pendidikan di pesantren dan sudah mumpuni dalam ilmu agama dianjurkan untuk melakukan dakwah dalam menyebarkan agama Islam. Dan keturunan pedagang muslim yang menikahi pribumi Indonesia, ada yang memang sengaja di gembleng untuk menjadi pendakwah.

Dengan metode-metode tersebut para pendakwah yang rata-rata saudagar menyebarkan islam di nusantara yang lambat laun semakin banyak komunitas islam di berbagai daerah utamanya di pesisir, yang nantinya menjadi kerajaan kecil, dan pada kahirnya menjadi kerajaan besar yang berkuasa di nusanara.

Strategi dakwah dapat diartikan sebagai proses menentukan cara dan daya upaya untuk menghadapi sasaran dakwah dalam situasi dan kondisi tertentu guna 
mencapai tujuan dakwah secara optimal. Dengan kata lain strategi dakwah adalah siasat, taktik atau manuver yang ditempuh dalam rangka mencapai tujuan dakwah. ${ }^{2}$

Strategi yang disusun, dikonsentrasikan, dan dikonsepsikan dengan baik dapat membuahkan pelaksanaan yang disebut strategis. ${ }^{3}$ Menurut Hisyam Alie yang dikutip Rafi'udin dan Djaliel, untuk mencapai strategi yang strategis harus memperhatikan apa yang disebut SWOT sebagai berikut:

1. Strength (kekuatan), yakni memperhitungkan kekuatan yang dimiliki yang biasanya menyangkut manusianya, dananya, beberapa piranti yang dimiliki.

2. Weakness (kelemahan), yakni memperhitungkan kelemahan-kelemahan yang dimilikinya, yang menyangkut aspek-aspek sebagaimana dimiliki sebagai kekuatan, misalnya kualitas manusianya, dananya, dan sebagainya.

3. Opportunity (peluang), yakni seberapa besar peluang yang mungkin tersedia di luar, hingga peluang yang sangat kecil sekalipun dapat diterobos.

4. Threats (ancaman), yakni memperhitungkan kemungkinan adanya ancaman dari luar. ${ }^{4}$

Faktor-faktor diatas merupakan faktor yang harus dipertimbangkan dalam berdakwah. Yang pertama yakni kekuatan, dengan memperhitungkan kekuatan yang dimiliki, seorang dai bisa lebih menempatkan diri dengan baik. Dai bisa mengukur seberapa besar sumber daya yang ia miliki untuk berjuang dalam berdakwah. Sumber daya yang dimaksud disini baik berupa keilmuan, finansial, sarana dan prasarana.

Kemudian yang kedua seorang dai harus mempertimbangkan kelemahannya sendiri, agar tau nantinya jika terjadi hambatandlam berdakwah, sang dai bisa mengantisipasi terlebih dahulu jika sudah mengetahui kelemahan sendiri, dan nantinya masalah tersebut dapat diatasi dan ditemukan jalan keluarnya dengan mudah.

\footnotetext{
${ }^{2}$ Awaluddin Pimay, Paradigma Dakwah Humanis: Strategi Dan Metode Dakwah Prof KH Syaifudin Zuhri (Semarang: Rasail, 2005). 50

${ }^{3}$ Rafiuddin and Mannan Abdul Jalil, Prinsip Dan Strategi Dakwah (Bandung: Pustaka Setia, 1997).76

${ }^{4}$ Ibid.77
} 
Lalu yang ketiga peluang. Peluang juga harus dipertimbangkan. Peluang dakwah diterima pada golongan masyaraat sasaran itu besar apa kecil. Jika peluang dakwah tersebut besar maka strategi yang akan dipakai berbeda dengan dakwah yang peluang diterimanya kecil.

Yang terakhir seorang dai harus juga memperhitungkan ancaman yang bisa saja ia dapatan ketika sedang berdakwah. Dalam memperjuangkan agama tentu saja akan ada rintangan-rintangan dan ancaman yang datang. Karena itu ancaman juga harus diperhitungkan dengan cermat.

Berkaitan dengan strategi dakwah Islam, maka diperlukan pengenalan yang tepat dan akurat terhadap realitas hidup manusia yang secara aktual berlangsung dalam kehidupan dan mungkin realitas hidup antara satu masyarakat dengan masyarakat lain berbeda. Di sini, juru dakwah dituntut memahami situasi dan kondisi masyarakat yang terus mengalami perubahan, baik secara kultural maupun sosialkeagamaan. Strategi dakwah semacam ini telah diperkenalkan dan dikembangkan oleh Rasulullah Muhammad SAW dalam menghadapi situasi dan kondisi masyarakat Arab saat itu. Strategi dakwah Rasulullah yang dimaksud antara lain menggalang kekuatan di kalangan keluarga dekat dan tokoh kunci yang sangat berpengaruh di masyarakat dengan jangkauan pemikiran yang sangat luas, melakukan hijrah ke Madinah untuk fath al-Makkah dengan damai tanpa kekerasan, dan lain sebagainya. ${ }^{5}$

Kemudian, jika dikaitkan dengan era globalisasi saat ini, maka juru dakwah harus memahami perubahan transisional dari transaksi pada kekuatan magis dan ritual ke arah ketergantungan pada sains dan kepercayaan serta transisi dari suatu masyarakat yang tertutup, sakral dan tunggal ke arah keterbukaan, plural dan sekuler. Jadi, suatu strategi tidak bersifat universal. la sangat tergantung pada realitas hidup yang sedang dihadapi. Karena itu, strategi harus bersifat terbuka terhadap segala kemungkinan perubahan masyarakat yang menjadi sasaran dakwah. ${ }^{6}$

Berkaitan dengan perubahan masyarakat yang berlangsung di era globalisasi, maka perlu dikembangkan strategi dakwah Islam sebagai berikut. Pertama,

\footnotetext{
${ }^{5}$ Ibid.78

${ }^{6}$ Pimay, Paradigma Dakwah Humanis: Strategi Dan Metode Dakwah Prof KH Syaifudin Zuhri.53
} 
meletakkan paradigma tauhid dalam dakwah. Pada dasarnya dakwah merupakan usaha penyampaian risalah tauhid yang memperjuangkan nilai-nilai kemanusiaan yang universal (egaliter, keadilan dan kemerdekaan). Dakwah berusaha mengembangkan fitrah dan kehanifan manusia agar mampu memahami hakekat hidup yang berasal dari Allah dan akan kembali kepada-Nya. Dengan mengembangkan potensi atau fitrah dan kedhaifan manusia, maka dakwah tidak lain merupakan suatu proses memanusiakan manusia dalam proses transformasi sosiokultural yang membentuk ekosistem kehidupan. Karena itu, tauhid merupakan kekuatan paradigmatis dalam teologi dakwah yang akan memperkuat strategi dakwah.

\section{METODE PELAKSANAAN KEGIATAN}

Metode pelaksanaan kegiatan ini dilakukan dengan pendekatan metode ceramah, partisipatif, pendekatan kelompok, metode diskusi/Forum Group Discussion (FGD) dan pendampingan. Metode ceramah dilakukan dengan tujuan memberikan pendampingan masyarakat dalam berdakwah yang cocok susuai kondisi Desa Kayukebek, Kecamatan Tutur, Kabupaten Pasuruan. Dalam kegiatan ini dilakukan dengan cara observasi langsung pada masyarakat. Dan menghasilkan bahwa cara yang persuasive dan fleksibel lebih bisa diterima masyarakat, hal ini dibuktikan dengan antusisme masyarakat untuk mengikuti kajian-kajian dakwah dengan strategi tersebut.

\section{HASIL DAN PEMBAHASAN}

Desa Kayukebek terletak di lereng gunung Bromo, Tepatnya di Kecamatan Tutur Kabupaten Pasuruan Jawa Timur. Mempunyai penduduk yang mayoritas muslim dan sisanya beragama hindu juga masih banyak masyarakat islam yang sangat awam tentang permasalahan agama membuat dakwah islam menjadi tantangan tersendiri disana.

Lingkungan dan suasana pedesaan yang tentram tentunya juga memengaruhi perilaku dan sifat masyarakat. Kerukunan dan toleransi antar ummat beragama sangat terjaga dengan baik. Hampir tidak pernah ada gesekan yang terjadi antara umat islam 
dan hindu selama ini. Hal itu juga merupakan salah satu faktor yang membuat dakwah islam bisa dengan tenang disebarkan dan diterima oleh banyak orang.

Para Dai di Desa Kayukebek menggunakan cara-cara yang persuasif untuk menyebarkan dakwah islam, sehingga masyarakat awam dapat dengan nyaman memperoleh ilmu. Penulis pribadi yang juga merupakan salah satu Dai di desa Kayukebek tidak pernah menggunakan cara-cara yang 'kasar' dan kaku untuk berdakwah. Yang mana jika hal itu dilakukan, masyarakat awam akan menghindar dan pada akhirnya akan semakin sulit untuk dirangkul.

Hukum-hukum syariat yang dipakai dalam menjawab persoalan masyarakat pun juga menggunakan hukum yang luwes dan tidak kaku. Tujuannya agar masyarakat merasa nyaman terlebih dahulu baru kemudian diberi dakwah-dakwah yang menyejukkan. Hal ini terbuki efektf dan tepat untuk digunakan di Desa Kayukebek. Yang mana hal ini dapat dilihat dari antusiasme masyarakat untuk mengikuti pengajianpengajian dan perkumpulan yang diselenggarakan secara rutin oleh para Dai disana.

Penulis sendiri memiliki beberapa agenda rutinan yang ada di Desa kayukebek, baik di Dusun Taman, Dusun Karang Rejo, Dusun Ledok dan Dusun Ngaruh. Baik dai jamaah lai-lai, perempuan dan ibu-ibu, atau juga para pemuda seperti IPNU dan IPPNU. Semua itu menunjukkan strategi yang digunakan oleh para dai sudah berhasil dan tepat sasaran.

Berikut tabel jadwal rutinan pengajian yang diisi oleh penulis di Desa Kayukebek:

\begin{tabular}{|l|l|l|l|}
\hline \multicolumn{1}{|c|}{ Hari } & \multicolumn{1}{|c|}{ Jam } & \multicolumn{1}{c|}{ Jamaah } & \multicolumn{1}{c|}{ Tempat } \\
\hline Selasa & 18.00 -selesai & Pemuda putra & Dsn Ledok \\
\hline Rabu & 19.00 -selesai & Jamaah Tahlil NU & Dsn Karang Rejo \\
\hline Jumat & 13.00 -selesai & muslimat & Dsn Ledok \\
\hline Sabtu & 15.00 -selesai & fatayat & Dsn Ngaruh \\
\hline Sabtu & 18.00 & Jamaah Ngaruh & Dsn Ngaruh \\
\hline
\end{tabular}

tabel 1. Jadwal rutin pengajian Hufron

Pendekatan dakwah yang persuasif dan juga luwes terbukti dapat dengan mudah diterima oleh masyarakat awam dengan baik. Hal ini juga bisa dilihat dari tidak adanya 
gesekan antar agama di Desa Kayukebek, yang mana penulis pribadi yang juga seorang Dai muslim, akrab dengan para tokoh agama hindu.

Dakwah persuasif sendiri ialah kegiatan berdakwah dengan menggunakan metode komunikasi persuasif yang bertujuan mengubah, memodifikasi atau membentuk respon (sikap atau perilaku) dari penerima atau mad'u. Tujuan itu akan berhasil manakala seorang dai mampu menyampaikan dakwahnya dengan pendekatan psikologis. Salah satu contoh metodologi dakwah dalam Alquran yaitu metode bi alhikmah. ${ }^{7}$

Dalam penyampaian pesan dakwah perlu diperhatikan juga pembicaraan (qaulan) yang dikategorikan sebagai prinsip komunikasi dakwah persuasif. Prinsipprinsip ini bersumberkan Alquran, diantaranya:

Pertama, prinsip qaulan layyinan. Kata qaulan Layyinan disebutkan dalam QS Thaahaa: 44 , yang berbunyi," Maka berbicaralah kamu berdua kepadanyna dengan kata kata yang lemah lembut, mudah mudahan ia ingat akan takut.”. Menurut Al-Maraghi (1943: 156) qaulan layyinan berarti pembicaraan yang lemah lembut agar lebih dapat menyentuh hati dan menariknya untuk menerima dakwah. Sedangkan menurut Ibnu Katsir (2000: 243) yang dimaksud layyinan ialah kata kata sindiran / bukan dengan kata kata terus terang. Menurut Al-Zuhaily (1991: 215 ) menafsirkan ayat, "Maka katakanlah kepadanya (Fir'aun) dengan tutur kata yang lemah lembut akan merasa takuk dengan siksa yang dijadikan oleh Allah melaui lisannya." Maksud ayat ini nabi Musa dan Nabi Harun diperintahkan Allah meninggalkan sikap yang kasar. Berdasarkan tiga pendapat di atas dapat istilah qaulan layyinan memiliki makna kata kata yang lemah lembut, suara yang enak didengar, sikap yang bersahabat, dan perilaku yang menyenangkan dalam menyerukan agama Allah. Dengan kata kata Qaulan Layyinan, orang yang diajak berkomunikasi akan merasa tersentuh hatinya, tergerak jiwannya dan tentram batinnya, sehingga akan mengikuti dakwah da'i.

Kedua, prinsip qaulan sadidan. Qaulan sadidan artinya pembicaraan yang benar, jujur, lurus, tidak bohong, dan tidak berbeli-belit. Kata qaulan sadidan disebut dua kali

\footnotetext{
${ }^{7}$ BM ST. Aisyah et al., "Bentuk Penerapan Dakwah Persuasif Terhadap Pembinaan Eks Pekerja Seks Komersial Di Panti Sosial Karya Wanita Mattirodeceng Kota Makassar," Jurnal Diskursus Islam 6, no. 1 (2018): 109-134.
} 
dalam Alquran. Pertama, Allah menyuruh manusia menyampaikan qaulan sadidan dalam urusan anak yatim dan keturunan. Kedua, Allah memerintahkan qaulan sadidan sesudah takwa. Contoh qaulan sadidan yaitu tidak berbohong karena Kebohongan tentulah sangat merugikan banyak pihak. Dalam perkembangan kehidupan manusia, tidak terlepas dari bohong. Sejak zaman Nabi Muhammad pun, kebohongan merambah pada periwayatan hadis-hadis nabi. Sejatinya, hadis adalah dasar hukum kedua setelah Alquran. Memalsukan hadis nabi, berarti memalsukan agama Islam, termasuk di dalamnya hukum-hukum Islam. Namun, kebohongan tidak akan pernah bisa memasuki Alquran, karena keaslian Alquran dijamin oleh Allah.

Ketiga, prinsip qaulan maysuran. Kata qaulan maysuran hanya satu kali disebutkan dalam Alquran, QS. Al-Israa': 28. Berdasarkan sebab-sebab turunnya (asbab al-nuzul) ayat tersebut, Allah memberikan pendidikan kepada Nabi Muhammad Saw untuk menunjukkan sikap yang arif dan bijaksana dalam menghadapi keluarga dekat, orang miskin dan musafir. Secara etimologis, kata maysuran berasal dari kata yasara yang artinya mudah atau gampang. Ketika kata maysuran digabungkan dengan kata qaulan menjadi qaulan maysuran yang artinya berkata dengan mudah atau gampang. Berkata dengan mudah maksudnya adalah kata-kata yang digunakan mudah dicerna, dimengerti, dan dipahami oleh komunikan. Salah satu prinsip komunikasi dalam Islam adalah setiap berkomunikasi harus bertujuan mendekatkan manusia dengan Tuhannya dan hamba-hambanya yang lain. Islam mengharamkan setiap komunikasi yang membuat manusia terpisah dari Tuhannya dan hambahambanya. Seorang komunikator yang baik adalah komunikator yang mampu menampilkan dirinya sehingga disukai dan disenangi orang lain. Untuk bisa disenangi orang lain, ia harus memiliki sikap simpati dan empati. Simapti dapat diartikan dengan menempatkan diri kita secara imajinatif dalam posisi orang lain. Namun dalam komunikasi, tidak hanya sikap simpati dan empati yang dianggap penting karena sikap tersebut relatif abstrak dan tersembunyi, tetapi juga harus dibarengi denganpesan-pesan komunikasi yang disampaikan secara bijaksana dan menyenangkan. (penuh persaudaraan) dan manis didengar, tidak menampakkan kekerasan dan nasihatilah dia dengan ucapan yang lemah lembut agar dia lebih tertarik karena dia 
Keempat, prinsip qaulan baligha, yaitu ucapan yang lugas, efektif, dan tidak berbelit-belit (QS An-Nissa : 63).

Kelima, Prinsip qulan ma'rufa, yaitu perkataan yang baik, santun, dan tidak kasar (QS An-Nissa: 5, QS. Al-Baqarah: 235, 263, dan QS. Al-Ahzab: 32). Dan Kelima, prinsip qaulan karima, artinya kata-kata yang mulia dan penuh penghormatan (QS. Al-Isra: 23). ${ }^{8}$

Aktivitas dakwah dapat membentuk perubahan-perubahan sosial (masyarakat) yang dapat diidentikkan dengan proses mencakup segenap cara berpikir dan bertingkah laku yang muncul karena interaksi yang bersifat komunikatif seperti menyampaikan pesan dakwah secara simbolis.

Perubahan-perubahan perilaku yang terjadi masyarakat, tidak sekaligus tetapi melalui proses, yaitu: terbentuknya suatu pengertian atau pengetahun, proses suatu sikap menyetujui atau tidak menyetujui, proses terbentuknya gerak pelaksanaan. Jadi, dengan menerima pesan dakwah, diharapkan masyarakat sebagai mad'u dapat mengubah cara berpikirnya tentang ajaran agama sesuai dengan pemahaman yang sebenarnya. Seseorang dapat memahami atau mengerti pesan dakwah setelah melalui proses berpikir. Dalam berpikir, seseorang mengolah, mengorganisasikan bagianbagian dari pengetahuan yang diperolehnya, dengan harapan pengetahuan dan pengalaman yang tidak beratur dapat tersusun rapi dan perulakan kebulatan yang dapat dikuasai dan dipahami. Berpikir ditentukan oleh bermacam-macam faktor yang dapat mempengaruhi jalannya berpikir.

Selanjutnya adanya perubahan sikap masyarakat sebagai mad'u setelah menerima pesan dakwah. Pada tahap ini masyarakat membuat keputusan untuk menerima atau menolak pesan dakwah. Maka pada aspek ini pesan dakwah yang diterima tersebut dapat mendorong masyarakat untuk melakukan secara nyata ajaranajaran Islam sesuai dengan pesan dakwah, maka dakwah dikatakn berhasil dengan baik, jika masyarakat sebagai mad'u memahami, dapat bersikap atau memberikan respon dan terakhir adanya perubahan perilaku masyarakat.

\footnotetext{
${ }^{8}$ Mubasyaroh Mubasyaroh, "Strategi Dakwah Persuasif Dalam Mengubah Perilaku Masyarakat," Ilmu Dakwah: Academic Journal for Homiletic Studies 11, no. 2 (2017): 311-324.
} 


\section{KESIMPULAN}

Kondisi geografis tentunya berpengaruh pada sifat dan kondisi sosial sebuah masyarakat. Kayukebek yang terletak di dataran tinggi lereng gunung bromo tentunya juga memengaruhi kondisi sosial yang juga berpengaruh pada strategi dakwah islam yang digunakan di daerah tersebut. Dengan kondisi masyarakat yang guyub, dan santun tentunya strategi yang cocok digunakan juga strategi yang luwes dan fleksibel agar bisa leboh diterima dan tepat pada sasaran.

Dakwah yang persuasif dan fleksibel terbukti lebih bisa diterima dengan banyanya antusisme masyarakat dalam mengikuti pengajian dan perkumpulan dakwah yang diisi oleh para dai sekitar. 


\section{DAFTAR PUSTAKA}

ST. Aisyah, BM, Muliaty Amin, Abd. Rasyid Masri, and Usman Jasad. "Bentuk Penerapan Dakwah Persuasif Terhadap Pembinaan Eks Pekerja Seks Komersial Di Panti Sosial Karya Wanita Mattirodeceng Kota Makassar." Jurnal Diskursus Islam 6, no. 1 (2018): 109-134.

Ilham. "Peranan Penyuluh Agama Islam Dalam Dakwah." Jurnal Alhadharah 17, no. 33 Januari-Juni (2018): 49-80.

Mubasyaroh, Mubasyaroh. "Strategi Dakwah Persuasif Dalam Mengubah Perilaku Masyarakat." Ilmu Dakwah: Academic Journal for Homiletic Studies 11, no. 2 (2017): 311-324.

Pimay, Awaluddin. Paradigma Dakwah Humanis: Strategi Dan Metode Dakwah Prof KH Syaifudin Zuhri. Semarang: Rasail, 2005.

Rafiuddin, and Mannan Abdul Jalil. Prinsip Dan Strategi Dakwah. Bandung: Pustaka Setia, 1997. 